\title{
DETERMINAÇÃO DA INFLUÊNCIA DA COMPOSIÇÃO DAS MISTURAS DESSULFURANTES DE FERRO-GUSA USANDO A TERMODINÂMICA COMPUTACIONAL*
}

\author{
Rodrigo de Oliveira Pezzin ${ }^{1}$ \\ Silas Gambarine Soares ${ }^{1}$ \\ Heitor Cristo Clem de Oliveira ${ }^{1}$ \\ Sábata Marla Reis Durães Oliveira ${ }^{2}$ \\ Felipe Fardin Grillo \\ Eduardo Junca ${ }^{3}$ \\ José Roberto de Oliveira ${ }^{4}$
}

\section{Resumo}

Devido ao fato que a exigência por menores teores de enxofre em alguns tipos de aços, torna-se interessante investigar a eficiência na dessulfuração dos materiais já conhecidos com matérias primas alternativas. Duas dessas novas matérias primas que podem ser utilizadas no processo de dessulfuração são o resíduo de mármore e a sodalita. Desta forma, o presente trabalho tem como objetivo avaliar a eficiência de dessulfuração em ferro-gusa por misturas contendo resíduo de mármore, sodalita e agentes dessulfurantes convencionalmente utilizados. Os testes foram realizados a $1400^{\circ} \mathrm{C}$, em uma atmosfera inerte (Ar) com agitação constante. Os testes experimentais mostraram que 50 a $90 \%$ da dessulfuração ocorreu em até 15 minutos. As misturas contendo fluorita foram os que apresentaram maior eficiência de dessulfuração. A adição de sodalita ocasionou uma queda na eficiência de dessulfuração.

Palavras-chave: Dessulfuração; Sodalita; Resíduo de mármore.

\section{DETERMINATION OF THE INFLUENCE OF HOT METAL DESULFURIZING MIXTURES COMPOSITION USING COMPUTATIONAL THERMODYNAMICS \\ Abstract}

Due to fact that lesser sulfur content is required in steel, investigate the desulfurization efficiency from alternative raw materials become interesting. Two of these raw materials that can be used in the desulfurization process are marble waste and sodalite. Thus, the aim of this paper is to evaluate the desulfurization efficiency in pig iron for mixtures containing marble waste, sodalite and desulfurizing agents conventionally used. The tests were performed at $1400^{\circ} \mathrm{C}$. Argon was used to create an inert atmosphere. In addition, the bath was agitated constantly. The essays showed that 50 to $90 \%$ of sulfur was removed up to 15 minutes. The mixtures containing fluorite showed higher desulfurization efficiency. The addition of sodalite caused a decrease on desulfurization efficiency.

Keywords: Desulfurization; Sodalite; Marble waste.

1 Engenheiro Metalurgista, Mestrando em Engenharia Metalúrgica e de Materiais, PROPEMM, Instituto Federal de Educação, Ciência e Tecnologia do Espírito Santo (IFES), Vitória, Brasil.

2 Mestre em Engenharia Metalúrgica e de Materiais, PROPEMM, Instituto Federal de Educação, Ciência e Tecnologia do Espírito Santo (IFES), Vitória, Brasil.

3 Doutor em Engenharia Metalúrgica e de Materiais - USP, Pós-doutorando no Instituto Federal de Educação, Ciência e Tecnologia do Espírito Santo (IFES), Vitória, Brasil.

4 Professor Doutor do programa de pós-graduação em Engenharia Metalúrgica e de Materiais (PROPEMM) do Instituto de Educação, Ciência e Tecnologia do Espírito Santo (IFES), Vitória, Brasil. 


\section{INTRODUÇÃO}

As exigências cada vez mais rigorosas do mercado consumidor de aço, principalmente com os teores residuais de elementos indesejáveis, tem levado as siderúrgicas a investirem nos processos de pré-tratamento do gusa líquido.

O enxofre é considerado um elemento indesejável no aço por ser prejudicial às propriedades mecânicas, pois provoca uma redução da resistência ao choque (tenacidade), diminuição da aceitação ao dobramento, baixa estampabilidade e fragilidade à quente devido à formação de sulfetos. Porém, a formação de sulfetos, principalmente o sulfeto de manganês (MnS), pode ser benéfica para a usinabilidade do aço. Por isso, tem sido comum em aços para a indústria automobilística, especificar faixas para o teor de enxofre entre 0,015 e 0,030\%, ao invés de apenas especificar um valor máximo, como era feito até a década de 90 [1].

De acordo com Campos (1985) [2] a fonte principal de enxofre para o ferro-gusa é o coque, mas também pode estar presente no minério de ferro na forma de sulfetos como FeS, MnS e FeS2.

A remoção de enxofre no alto forno é favorecida devido à existência de uma atmosfera redutora e a carga metálica contendo outros elementos dissolvidos, como carbono e silício, que aumentam a atividade henriana do enxofre, além da baixa concentração de oxigênio. Porém, os valores de enxofre no ferro-gusa líquido não atendem às exigências dos aços mais modernos.

Assim, faz-se necessário um pré-tratamento do ferro-gusa líquido entre o alto-forno e a aciaria. Na maioria das siderúrgicas, o ferro-gusa é dessulfurado no prétratamento e parte da produção de aço é outra vez dessulfurada na panela de refino secundário. Assim, em alguns casos, a dessulfuração é segmentada em três etapas: parte no carro torpedo ou no $\mathrm{KR}$, parte no próprio conversor e parte na panela de refino secundário [3].

A reação de dessulfuração pode ser representada pela Equação 1. O oxigênio liberado pela Equação 1 [4], reage com o carbono e silício contido no ferro-gusa, como é visto nas Equações 2 e 3 [5].

$$
\begin{array}{r}
\underline{\mathrm{S}}+\mathrm{CaO}_{(\mathrm{s})}=\mathrm{CaS}_{(\mathrm{s})}+\underline{\mathrm{O}} \\
\underline{\mathrm{S}}+\underline{\mathrm{C}}+\mathrm{CaO}_{(\mathrm{s})}=\mathrm{CaS}_{(\mathrm{s})}+\mathrm{CO}_{(\mathrm{g})} \\
\mathrm{CaO}(\mathrm{s})+\underline{\mathrm{s}}+1 / 2 \underline{\mathrm{Si}}=\mathrm{CaS}_{(\mathrm{s})}+\mathrm{SiO}_{2(\mathrm{~s})}
\end{array}
$$

Os agentes dessulfurantes mais utilizados na dessulfuração do ferro-gusa líquido são a cal e o carbureto de cálcio. O magnésio também é utilizado, porém sua ação é de desoxidação. Um dos componentes utilizados para dessulfuração são os agentes fluidizantes, como por exemplo, a fluorita e a nefelina, que diminuem o ponto de fusão das escórias e aumentam sua fluidez [6].

O resíduo de mármore aparece como um possível substituto da cal, uma vez que é composto principalmente por carbonato de cálcio e magnésio. Já a nefelina é, essencialmente, um sílico-aluminato enriquecido em álcalis $\left(\mathrm{Na}_{2} \mathrm{O}\right.$ e $\left.\mathrm{K}_{2} \mathrm{O}\right)$. Apresenta teores em torno de $50 \%$ de $\mathrm{SiO}_{2}, 23 \%$ de $\mathrm{Al}_{2} \mathrm{O}_{3}, 12 \%$ de $\mathrm{Na}_{2} \mathrm{O}, 5 \%$ de $\mathrm{K}_{2} \mathrm{O}$ e residuais de $\mathrm{Fe}_{2} \mathrm{O}_{3}, \mathrm{MgO}, \mathrm{CaO}$ e $\mathrm{TiO}_{2}$. No estado líquido, essas fases reagem provavelmente como recipientes para as fases do sulfeto. A formação de fases eutéticas pode ser excluída devido à pequena parte na mistura [7].

A nefelina pode ser utilizada em duas etapas do processo de fabricação de aço: no convertedor ou na metalurgia da panela. Cabe ressaltar um fator positivo na utilização da nefelina em relação à fluorita. O teor de sílica presente nesse mineral 
impede a utilização em excesso, pois este teor elevado altera as propriedades da escória, prejudicando as reações do refino. A fluorita, quando utilizada em excesso, não altera as propriedades das escórias, no tocante às reações de refino, porém, eleva em demasiado o desgaste refratário, ou seja, o excesso de fluorita pode trazer um efeito cinético positivo com prejuízo para os custos de refratários das aciarias [8]. Desta forma, este trabalho tem como objetivo avaliar a eficiência de dessulfuração em ferro-gusa por misturas contendo sodalita, resíduo de mármore e agentes dessulfurantes convencionalmente utilizados.

\section{MATERIAIS E MÉTODOS}

\subsection{Definição das misturas}

As misturas dessulfurantes foram definidas a partir da composição química das matérias primas. Como fonte de $\mathrm{CaO}$, foram utilizadas a cal e o resíduo de mármore, e como agente fluxante a fluorita e sodalita.

As misturas sem resíduo de mármore foram elaboradas com diferentes percentuais de sílica.

A partir dessas informações foram elaboradas seis misturas contendo fonte de $\mathrm{CaO}$ e variando-se os agentes fluxantes (fluorita e nefelina), e 4 misturas utilizando resíduo de mármore aonde também variou-se os agentes fluxantes. As composições químicas das misturas dessulfurantes são apresentadas na Tabela 1.

Tabela 1. Composição química das escórias dessulfurantes propostas utilizando cal, resíduo de mármore, fluorita e nefelina

\begin{tabular}{|c|c|c|c|c|c|c|c|}
\hline \multirow{2}{*}{ Mistura } & \multicolumn{6}{|c|}{ Composição Química (\% em massa) } & \multirow{2}{*}{$\begin{array}{l}\text { Massa de } \\
\text { mistura (g) }\end{array}$} \\
\hline & $\mathrm{CaO}$ & $\mathrm{Na}_{2} \mathrm{O}$ & $\mathrm{CaF}_{2}$ & $\mathrm{Al}_{2} \mathrm{O}_{3}$ & MgO & $\mathrm{SiO}_{2}$ & \\
\hline F5 & 92,5 & - & 4,7 & 0,42 & - & 2,49 & 9,26 \\
\hline F10 & 87,4 & - & 8,7 & 0,6 & - & 2,8 & 9,28 \\
\hline N5 & 92,7 & 0,7 & - & 1,5 & - & 4,9 & 9,21 \\
\hline N10 & 87,3 & 1,3 & - & 2,8 & - & 7,62 & 9,19 \\
\hline F5-S & 89,35 & - & 4,7 & 0,42 & - & 5,5 & 9,58 \\
\hline F10-S & 84,12 & - & 9,13 & 0.62 & - & 5,8 & 9,64 \\
\hline RMF5 & 67,8 & - & 1,95 & - & 24,4 & 5,77 & 5,57 \\
\hline RMF10 & 66,3 & - & 4,04 & - & 23,9 & 5,75 & 5,57 \\
\hline RMN5 & 67,8 & 0,29 & - & 0,51 & 24,5 & 6,86 & 5,57 \\
\hline RMN10 & 66,2 & 0,61 & - & 1,06 & 23,8 & 8,03 & 5,57 \\
\hline
\end{tabular}

Como pode ser observado na tabela 1 foram usadas misturas com diferentes teores de $\mathrm{CaF}_{2}, \mathrm{CaO}, \mathrm{SiO}_{2}$ e $\mathrm{Al}_{2} \mathrm{O}_{3}$, porém esses teores são próximos aos utilizados industrialmente. As misturas F5 e F10 foram feitas com adição de 5 e 10\% de fluorita, respectivamente. As misturas F5-S e F10-S tiveram adição de $3 \%$ de $\mathrm{SiO}_{2}$ nas misturas F5 e F10. As misturas N5 e N10 foram feitas com adição de 5 e 10\% de nefelina. Às misturas com resíduo de mármore também foram acrescentas $5 \mathrm{e}$ $10 \%$ de fluorita (RMF5 e RMF10) e 5 e 10\% de nefelina (RMN5 e RMN10).

A relação entre massa de mistura adicionada ao ferro-gusa normalmente utilizada industrialmente é de $10 \mathrm{~kg} /$ tonelada, no presente trabalho foi considerada a relação em escala laboratorial de 10 gramas de mistura por $1 \mathrm{~kg}$ de ferro-gusa, porém como pode ser observado na tabela 1 , ocorrem perdas ao adicionar as misturas 
dessulfurantes no banho devido à presença de materiais voláteis ou perdas por calcinação.

O ferro-gusa utilizado foi fornecido pela empresa Tecnosulfur. Sua composição química é mostrada na Tabela 2.

Tabela 2. Composição química do ferro-gusa utilizado nos experimentos

\begin{tabular}{cccccc}
\hline \multirow{2}{*}{ Misturas } & \multicolumn{5}{c}{ Composição Química Inicial (\%) } \\
\cline { 2 - 6 } & $\mathbf{C}$ & Mn & Si & $\mathbf{P}$ & $\mathbf{S}$ \\
\hline F5 & 4,5 & 0,21 & 0,5 & 0,13 & 0,028 \\
F10 & 4,47 & 0,18 & 0,48 & 0,11 & 0,031 \\
N5 & 4,44 & 0,19 & 0,47 & 0,13 & 0,036 \\
N10 & 4,52 & 0,19 & 0,51 & 0,12 & 0,028 \\
F5-S & 4,48 & 0,21 & 0,5 & 0,13 & 0,028 \\
F10-S & 4,49 & 0,19 & 0,48 & 0,11 & 0,031 \\
RMF5 & 4,5 & 0,21 & 0,54 & 0,13 & 0,029 \\
RMF10 & 4,47 & 0,18 & 0,49 & 0,12 & 0,03 \\
RMN5 & 4,5 & 0,22 & 0,53 & 0,13 & 0,0285 \\
RMN10 & 4,42 & 0,19 & 0,48 & 0,1 & 0,0305 \\
\hline
\end{tabular}

\subsection{Testes experimentais}

Os testes foram realizados em forno de resistência elétrica modelo MEV 1500/Z da empresa FORTELAB (Indústria de Fornos Elétricos LTDA). Esse forno tem potência de $5000 \mathrm{~W}$, tensão de 220 volts, corrente de 25 amperes e temperatura máxima de $1500^{\circ} \mathrm{C}$. A Figura 1 apresenta um diagrama esquemático da realização dos experimentos.

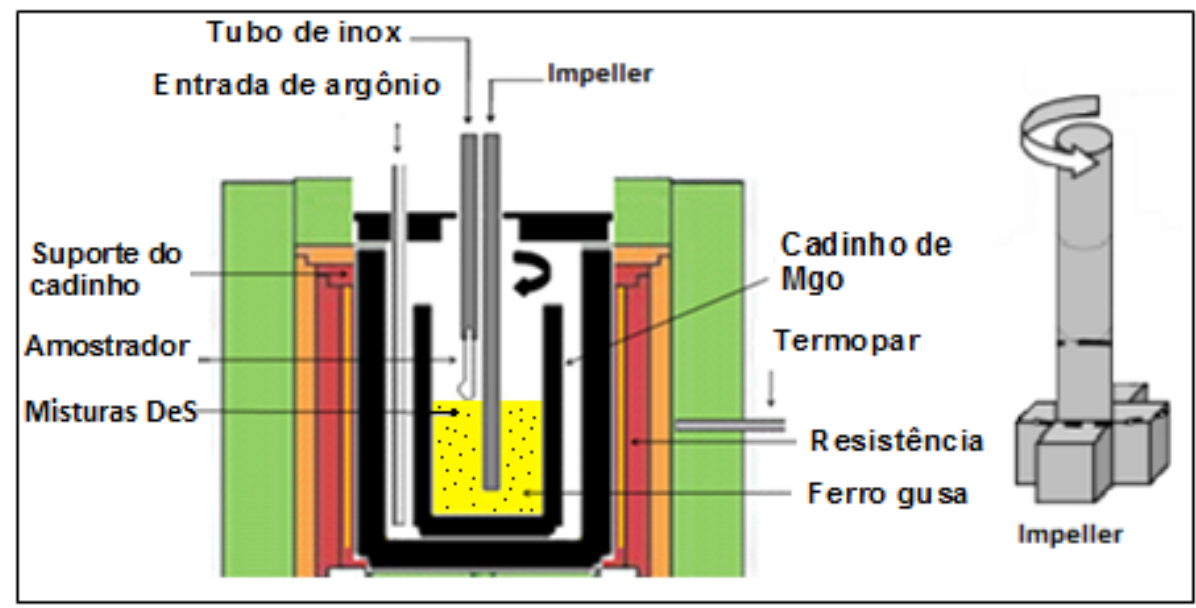

Figura 1. Diagrama Esquemático da realização dos experimentos

O ferro-gusa sólido foi carregado em um cadinho de $\mathrm{MgO}-\mathrm{C}$ e colocado dentro do forno com o auxílio de uma tenaz a $1400^{\circ} \mathrm{C}$. Então, gás argônio foi injetado, numa vazão de $10 \mathrm{NI} / \mathrm{min}$, a fim de inertizar a atmosfera e evitar a oxidação do metal. Após a fusão, foi retirada uma amostra inicial, com o auxílio de um amostrador a vácuo, a fim de analisar a composição química inicial do mesmo. Então, a mistura dessulfurante foi adicionada sobre o ferro-gusa. A retirada de amostras foi realizada em 10, 15, 20 e 30 minutos após a adição da mistura. Em adição, um agitador mecânico foi acoplado ao forno para promover uma homogeneização do banho. 


\subsection{Cálculo da eficiência de dessulfuração}

A eficiência de dessulfuração foi calculada a partir dos valores iniciais e finais de enxofre após cada ensaio. A eficiência de dessulfuração foi obtida via Equação 4.

$$
\operatorname{Eficiência}(\eta \%)=\frac{\left(\left[\% S_{i}\right]-\left[\% S_{f}\right\rfloor\right)}{\left[\% S_{i}\right]} \times 100
$$

\subsection{Simulações no software Thermocalc}

Com o auxílio da termodinâmica computacional, utilizando o programa ThermoCalc v.5 foram realizadas simulações do aquecimento das misturas propostas a $1400^{\circ} \mathrm{C}$ de maneira a se caracterizar as misturas dessulfurantes iniciais e as escórias finais, obtendo assim, bem como seus respectivos teores no equilíbrio, a fração de líquido e sólidos, as fases presentes na fase líquida e sólida.

\section{RESULTADOS E DISCUSSÃO}

Os valores da variação de enxofre com o tempo de retirada de amostra são listados na Tabela 3.

Tabela 3. Variação da concentração de enxofre com o tempo

\begin{tabular}{ccccccccccc}
\hline $\begin{array}{c}\text { Tempo } \\
\text { (min) }\end{array}$ & F10 & F5 & RMF10 & RMF5 & N5 & F5-S & F10-S & RMN5 & RMN10 & N10 \\
\hline $\mathbf{0}$ & 0,0319 & 0,0286 & 0,0303 & 0,0291 & 0,0360 & 0,0286 & 0,0318 & 0,0287 & 0,0305 & 0,0282 \\
$\mathbf{1 0}$ & 0,0054 & 0,0019 & 0,0177 & 0,0203 & 0,0088 & 0,0070 & 0,0092 & 0,0189 & 0,0217 & 0,0180 \\
$\mathbf{1 5}$ & 0,0030 & 0,0011 & 0,0116 & 0,0142 & 0,0070 & 0,0062 & 0,0062 & 0,0103 & 0,0158 & 0,0131 \\
$\mathbf{2 0}$ & 0,0015 & 0,0010 & 0,0067 & 0,0092 & 0,0061 & 0,0053 & 0,0052 & 0,0770 & 0,0111 & 0,0107 \\
$\mathbf{3 0}$ & 0,0009 & 0,0010 & 0,0029 & 0,0040 & 0,0051 & 0,0042 & 0,0047 & 0,0053 & 0,0065 & 0,0072 \\
\hline
\end{tabular}

A Figura 2 mostra a variação da concentração de enxofre com o tempo.

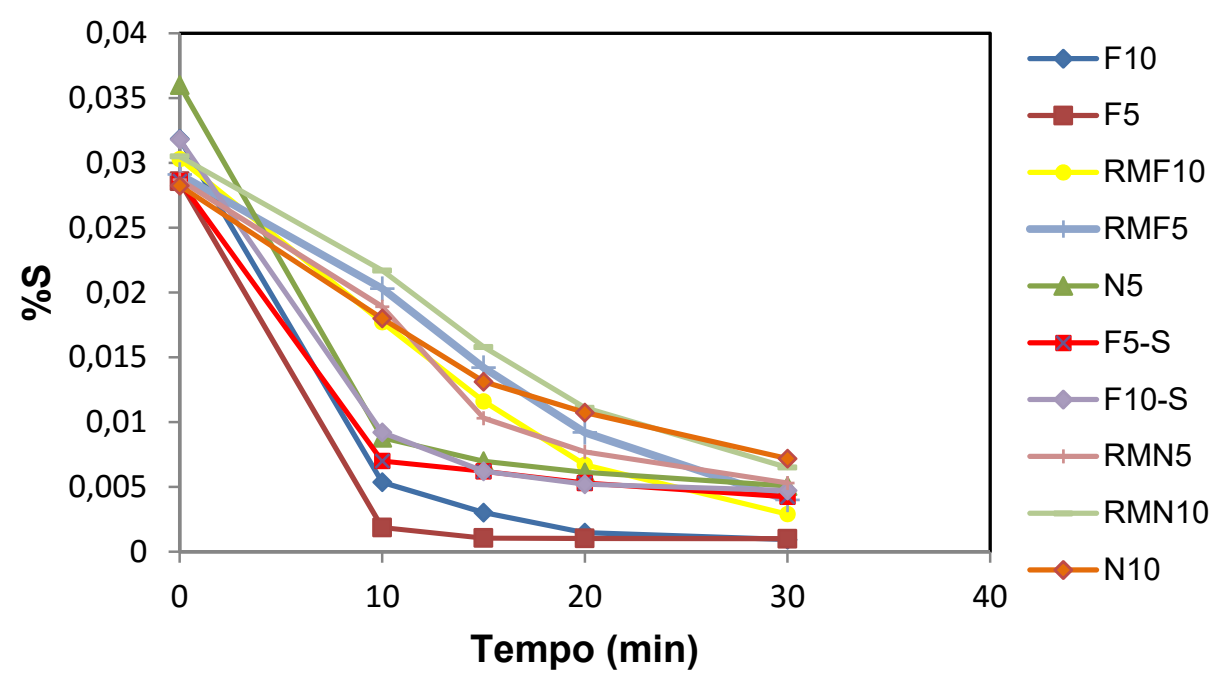

Figura 2. Variação da concentração de enxofre com o tempo 
Analisando a Figura 2, observa-se que a velocidade de dessulfuração das misturas $(\Delta S / \Delta t)$, foi maior e constante até os primeiros 10 minutos de experimento, ocorrendo neste período a maior parte da dessulfuração (de 50 a 90\%). Após 15 minutos, foi observado uma queda na velocidade de dessulfuração.

A partir dos dados de enxofre inicial e final, calculou-se a eficiência da dessulfuração alcançada pelas misturas dessulfurantes. Este cálculo foi feito de acordo com a Equação 4.

A Tabela 4 apresenta os valores de concentração de enxofre inicial e final e os valores da eficiência de cada mistura dessulfurante.

Tabela 4. Concentração de enxofre inicial e final obtido nos testes experimentais e a eficiência da reação de dessulfuração

\begin{tabular}{cccc} 
Mistura & \%Si & \%Sf & $\begin{array}{c}\text { Eficiência (n) } \\
\%\end{array}$ \\
\hline F10 & 0,0319 & 0,00093 & 97,1 \\
F5 & 0,0286 & 0,00099 & 96,4 \\
RMF10 & 0,0300 & 0,00290 & 90,3 \\
RMF5 & 0,0290 & 0,00400 & 86,2 \\
N5 & 0,0360 & 0,00506 & 85,9 \\
F5-S & 0,0286 & 0,00423 & 85,2 \\
F10-S & 0,0318 & 0,00471 & 85,2 \\
RMN5 & 0,0285 & 0,00530 & 81,4 \\
RMN10 & 0,0305 & 0,00653 & 78,6 \\
N10 & 0,0282 & 0,00718 & 74,6 \\
\hline
\end{tabular}

A fim de ter uma melhor visualização das eficiências obtidas nos testes experimentais, plotou-se um gráfico, como é visto na Figura 3.

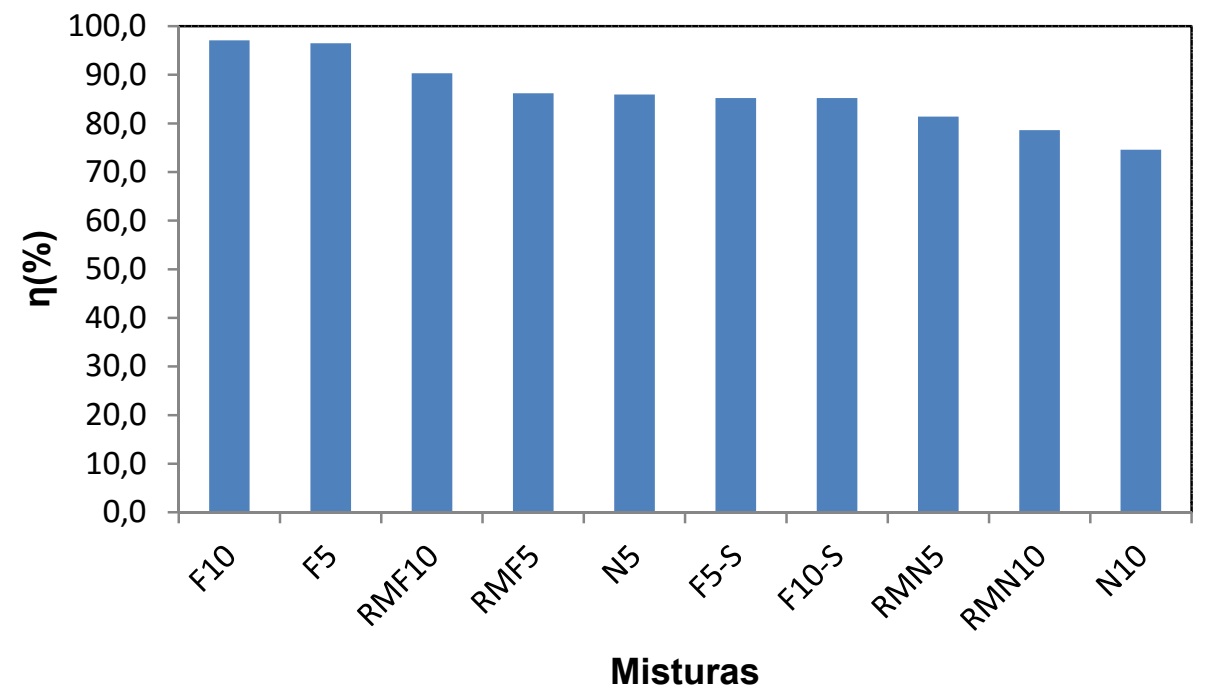

Figura 3. Eficiência de dessulfuração obtidos nos testes experimentais à $1400^{\circ} \mathrm{C}$

Observou-se que as misturas que obtiveram maior eficiência de dessulfuração foram a F10 e F5, com 97,1 e 96,4\%, respectivamente. Nas misturas formuladas com resíduo de mármore e fluorita, RMF10 e RMF5, foram encontrados valores de eficiência de 90,3 e 86,2\% respectivamente. As misturas F5-S e F10-S, com adição de $3 \%$ de $\mathrm{SiO}_{2}$, apresentaram uma eficiência de $85,2 \%$ para ambas misturas. As 
misturas do sistema com nefelina, N5, RMN5, RMN10 e N10, entretanto, apresentaram menor eficiência que aquela obtida para as misturas com fluorita, sendo de $85,9,81,4,78,6$ e $74,6 \%$, respectivamente. Observa-se que o aumento da adição de fonte de nefelina apresentou uma influência negativa na eficiência da dessulfuração, o que pode ser explicado pela maior quantidade de sílica em sua composição.

As misturas com adição de fluorita foram as mais eficientes, sendo aquelas com $10 \%$ melhores dessulfurantes que as com adição de $5 \%$. Porém, deve-se tomar cuidado com a quantidade de fluorita adicionada uma vez que a mesma em excesso pode causar um maior desgaste do revestimento refratário do equipamento, além de ser um composto nocivo ao meio ambiente.

A Tabela 5 mostra os resultados obtidos após o aquecimento das misturas dessulfurantes a $1400^{\circ} \mathrm{C}$ obtidas pelo software ThermoCalc.

Tabela 5. Propriedades das escórias obtidas com o software ThermoCalc

\begin{tabular}{cccccccc}
\hline \multirow{2}{*}{ Mistura } & \multirow{2}{*}{$\boldsymbol{\eta}(\%)$} & \multirow{2}{*}{ \%Líquido } & \multirow{2}{*}{ \%Sólido } & \multicolumn{5}{c}{ Fases formadas na Fase Sólida (\%) } \\
\cline { 5 - 8 } & & & & $\mathbf{C a O}$ & $\mathbf{3} \mathbf{C a O} . \mathbf{S i O}_{\mathbf{2}}$ & $\mathbf{3 C a O}_{\mathbf{3}} \mathbf{A l}_{\mathbf{2}} \mathbf{O}_{\mathbf{3}}$ & $\mathbf{\text { MgO }}$ \\
\hline F10 & 97,1 & 18,7 & 81,3 & 81,3 & 0 & 0 & 0 \\
F5 & 96,5 & 9,2 & 90,8 & 85,1 & 5,7 & 0 & 0 \\
RMF10 & 90,3 & 7,4 & 92,6 & 50,6 & 18,2 & 0 & 23,8 \\
RMF5 & 86,2 & 3,6 & 96,4 & 51,9 & 20,2 & 0 & 24,4 \\
N5 & 85,9 & 2,4 & 97,6 & 77,9 & 16,2 & 3,5 & 0 \\
F5-S & 85,2 & 8,8 & 91,2 & 74,5 & 16,6 & 0 & 0 \\
F10-S & 85,2 & 16,8 & 83,2 & 69,0 & 14,2 & 0 & 0 \\
RMN5 & 81,4 & 2,3 & 97,7 & 48,5 & 24,4 & 0,3 & 24,4 \\
RMN10 & 78,6 & 5,9 & 94,1 & 43,6 & 26,7 & 0 & 23,6 \\
N10 & 74,4 & 4,8 & 95,2 & 65,0 & 24,1 & 6,1 & 0 \\
\hline
\end{tabular}

É possível observar na Tabela 5 que para a maioria das misturas ocorreu uma redução da concentração de $\mathrm{CaO}$ sólido quando foi feita a simulação do aquecimento até $1400^{\circ} \mathrm{C}$. Isto ocorreu porque parte do $\mathrm{CaO}$ das misturas foi usado para formar os compostos sólidos $3 \mathrm{CaO} . \mathrm{SiO}_{2}$ e/ou $3 \mathrm{CaO} . \mathrm{Al}_{2} \mathrm{O}_{3}$ e parte foi usado para formar a fase líquida.

A Figura 4A, B e C apresenta a influência da fase líquida, da quantidade de $\mathrm{CaO}$ sólido e teor das fases sólidas $\left(3 \mathrm{CaO} . \mathrm{SiO}_{2}+3 \mathrm{CaO} \cdot \mathrm{Al}_{2} \mathrm{O}_{3}\right)$ sobre a eficiência de dessulfuração.
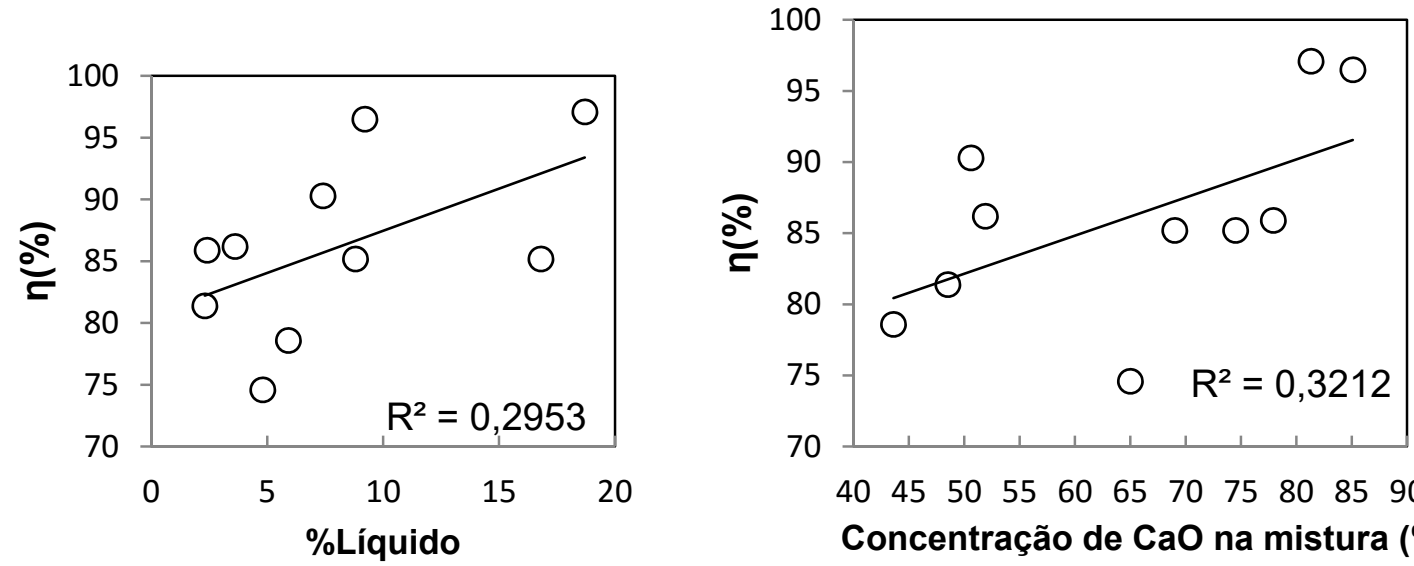

$\begin{array}{lllllllllll}40 & 45 & 50 & 55 & 60 & 65 & 70 & 75 & 80 & 85 & 90\end{array}$

Concentração de $\mathrm{CaO}$ na mistura (\%)

Figura 4. Influência do $\mathbf{A})$ teor de líquido, $\mathbf{B}) \mathrm{CaO}$ sólido e $\mathbf{C})$ fases sólidas $\left(3 \mathrm{CaO} \mathrm{SiO}_{2}\right.$ e $3 \mathrm{CaO} \cdot \mathrm{Al}_{2} \mathrm{O}_{3}$ ) na eficiência de dessulfuração. 


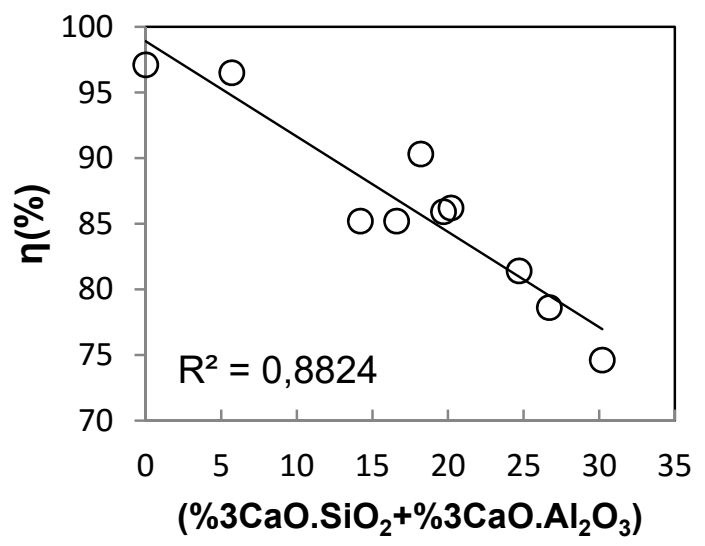

Pela Figura 4A é possível observar que quanto maior o teor de líquido, maior será a eficiência de DeS. Porém, a baixa correlação $\left(R^{2}=0,2953\right)$ é um indicativo de que nos processos estudados no presente trabalho, a fase líquida formada não tem influência direta na reação de dessulfuração, agindo somente na dissolução de parte da fase sólida formada. Analisando-se a Figura 4B tem-se que à medida que se aumenta a concentração de $\mathrm{CaO}$ sólido na mistura dessulfurante melhor será a eficiência da mistura dessulfurante. Já a Figura 4C mostra que o aumento da concentração de $3 \mathrm{CaO} . \mathrm{SiO}_{2}$ e $3 \mathrm{CaO} \cdot \mathrm{Al}_{2} \mathrm{O}_{3}$ na mistura acarreta a diminuição da eficiência. Tal fato é justificado pela limitação provocada pela formação de uma camada dessas fases ao redor da partícula de $\mathrm{CaO}$, que atua como uma barreira ao transporte de massa do enxofre contido no ferro-gusa até o $\mathrm{CaO} e$, consequentemente, prejudicando a reação de dessulfuração.

\section{CONCLUSÃO}

Os testes experimentais mostraram que a maior parte da dessulfuração (50 a 90\%) ocorreu até os dez primeiros minutos de reação, a partir do $15^{\circ}$ minuto a velocidade de dessulfuração diminuiu. Além disso, as misturas F10, F5, RMF10 e RMF5 mostraram-se mais eficazes no que tange a redução da concentração de enxofre do que as misturas N5, N10, RMN5 e RMN10, uma vez que foram as misturas que apresentaram maiores valores de eficiência.

As misturas RMN5, N5 e N10 foram as que apresentaram maiores teores de sólidos, dentre eles as fases $3 \mathrm{CaO} . \mathrm{SiO}_{2}$ e $3 \mathrm{CaO} . \mathrm{Al}_{2} \mathrm{O}_{3}$, fases estas que provocam uma diminuição da interface de reação entre o enxofre presente no metal líquido e as partículas de cal devido à formação de camadas ao redor das partículas de $\mathrm{CaO}$, isso pode ser explicado devido ao maior teor de sílica presente na composição dessas misturas.

\section{Agradecimentos}

Os autores agradecem a FAPES - Fundação de Amparo à Pesquisa e Inovação do Espírito Santo, processo 68853777/14. Os autores também agradecem ao Instituto Federal de Educação, Ciência e Tecnologia do Espírito Santo pelo apoio.

\section{REFERÊNCIAS}

1 COLPAERT, H. Metalografia dos produtos siderúrgicos comuns. 4. ed. São Paulo: Edgar Blucher, 2008, 171p. 
2 CAMPOS, V. F. Tecnologia de Fabricação do Aço Líquido. 3. ed. Belo Horizonte: Universidade Federal de Minas Gerais, 1985. 259 p.

3 CAMPOS, V. F. Curso sobre Pré-refino de Ferro-Gusa. 1. ed. Belo Horizonte: Universidade Federal de Minas Gerais, 1984. 31p.

4 ANDERSON, M.; JÖNSSON, P.; HALLBERG, M. Optimization of ladle slag composition by application of sulphide capacity model. Ironmaking and Steelmaking, n. 4, v. 27 , 2000. 286-293 p.

5 TURKDOGAN, E. Fundamentals of Steelmaking. London: The Institute of Materials, 1996.

6 SILVA, M. A. Avaliação da utilização de agentes dessulfurantes a base de carbureto de cálcio contendo sodalita em substituição à fluorita em carro torpedo. Dissertação de Mestrado em Engenharia Metalúrgica e de Minas, Belo Horizonte: UFMG, 2012. 98p.

7 SAMPAIO, J. A.; FRANÇA, S. C. A.; BRAGA, P. F. A. Nefelina Sienito. Comunicação Técnica elaborada para o livro Rochas Minerais Industriais: Usos e Especificações Parte 2 - Rochas e Minerais Industriais: Usos e Especificações. Capítulo 30. Rio de Janeiro, 2008, 663-680 p.

8 VOLKMANN, A. Utilização da sodalita-nefelínica em substituição a fluorita na aciaria da Usiminas. $33^{\circ}$ SEMINÁRIO DE FUSÃO, REFINO E SOLIDIFICAÇÃO DOS METAIS, ABM, Santos-SP, maio de 2002. 